\title{
How to Reap the Induced Technological Bonus? A Mechanism and Illustrative Implementation
}

\author{
Gouranga G. Das* \\ Department of Economics, Hanyang University, Seoul, South Korea \\ E-mail:gouranga_das@hotmail.com,dasgouranga@gmail.com \\ Received June 17, 2010; revised July 19, 2010; accepted July 23, 2010
}

\begin{abstract}
Exogenous technical progress can have uneven impacts on productivity contingent on absorptive capacity, structural congruence and trade intensity. The paper illustrates the role of enabling behind-the-border factors for effective absorption and is pertinent for discussing issues like 'Europe 2020'or Lisbon strategy for inclusive growth. Drawing on our model, we illustrate that the capture-parameter is the propellant force for effective assimilation of foreign technology of recent vintage. The capture parameter is the outcome of endogenous decision-making process. The 'productivity bonus' mechanism leaves room for changing the results via skill-mix composition. However, it awaits implementation in a large-scale economy-wide modeling framework for further extension.
\end{abstract}

Keywords: Trade, Technology Spillover, Capture, Productivity, Congruence

\section{Introduction}

Of late, with the rise to dominance of new endogenous growth theory the role of international trade and foreign direct investment (henceforth, FDI) in facilitating transborder technology flows and consequential rise in productivity can no way be underestimated. The role of international trade in transmission of technological benefits via traded intermediate inputs has been discussed at length in the literature - see Keller [1], Eaton and Kortum [2,3], Coe, Helpman and Hoffmaister [4,5]— to name a few. Participation in international trade provides a variety of benefits to developing countries through resource allocations according to comparative advantage, exploitation of economies of scale, increased capacity utilization and technology upgradation-to name a few. Upsurge in technology-intensive products is well-documented in the literature (Keller [1]; World Development Report [6], World Bank [7]; Connolly [8]; Coe et al. [4]; Guerrieri and Milana [9]; Hoekman and Javorcik [10]; Das [11-13]). In the literature of technology spillover, the importance of absorption capacity (AC) and structural similarity (SS) in appropriation of technological

${ }^{*}$ Comments of an anonymous referee is appreciated. With the usua disclaimer, the author is grateful to Professor Alan Powell. I acknowledge the support of the Faculty of Applied Economics, University of Antwerp, Belgium under Erasmus Mundus Visiting Scholar Programme of the European Commission during May-August 2010. benefits has been discussed (Cohen and Levinthal [14,15]; Nelson and Pack [16]; Evenson and Westphal [17]; World Development Report [6]). According to the World Development Report (World Bank [6] (henceforth, WDR) trade facilitates technology flows. WDR (1999) has documented evidences of acquisition of the knowledge capital with particular emphasis on the role of AC for knowledge diffusion. In fact, WDR (1999) reports that

"even a follower country needs a labour force with a relatively high level of technical education, especially when technologies are changing rapidly" (see p. 42, ibid).

Also, for closing 'knowledge gaps' between the technology creator and the recipients it emphasized the crucial roles of (see p. 25):

1) "Acquiring and adapting global knowledge —and creating knowledge locally;"

2) "Investing in human capital to increase the ability to absorb and use knowledge;"

3) "Investing in technologies to facilitate both the acquisition and the absorption of knowledge."

Development of AC is important for effective diffusion of technology as it encompasses the "ability to imitate new process of product innovations, [and] to exploit basic research." (Cohen and Levinthal, [15]).

Nelson [18] defines AC as

"the ability to learn and implement the technologies 
and associated practices of... ...developed countries."

Nelson and Pack [16] argues that

"to learn to use new technologies and to function effectively in new sectors required the development of new sets of skills, new ways of organising economic activity, and .... [becoming] competent in new markets" [and also] "to be sure, adopting technologies of the advanced countries required, among other things, high rates of investment in physical and human capital..."

We offer a stylized model formalizing the nexus between embodied technology transfer, human capital and TFP Growth. AC is defined in terms of skill intensity of the labor force (Das [12]; Meijl and Tongeren [19]). SS of two sectors will be judged by the similarity of their capital intensities, for example, by physical capital per unit of effective labor. SS involves comparison of structural characteristics of a sector in the source of technological change and those in the destinations; the idea is that the technical knowledge in the advanced economies will be most 'appropriate' to the clients closest to them in terms of their primary factor intensities. Our overarching theory focuses on the sector-specificity of the capture parameter $(\mathrm{CP})$ determined by $\mathrm{AC}, \mathrm{SS}$ and trade intensity (TI). The model developed is specifically designed for illustrative simulation of a technology shock. Section 2 rationalizes. Section 3 models. Section 4 numerically illustrates. Section 5 concludes.

\section{The Rationale}

Most of the relevant papers in the new growth literature deal with non-convexities in production and dynamic gains from trade between trade partners. ${ }^{1}$ The integration of new growth theory and trade theory à la Grossman and Helpman [21] and other researchers (mentioned above) places the emphasis on induced endogenous technical change and scale economies. Typically, most of the models assign a more prominent role to 'technological change' as an explanator for varying growth episodes across nations.

Lucas [22,23], however, is a tour de force in this genre of growth models where the role of human capital-modelled via schooling and formal education as well as learning by doing and on-the-job-training-has been given due importance. Kosempel [24] also modeled such interaction. In fact, Lucas [23] argues

"By assigning so great a role to 'technology' as a source of growth, the theory is obliged to assign correspondingly minor roles to everything else, and so has very little ability to account for the wide diversity in growth rates that we observe".

Lucas [22] argued that, although they started from almost entirely comparable bases, South Korea experi-

${ }^{1}$ See for example, Das [14,20], Grossman and Helpman [21], Evenson and Westphal [18]. enced a 'growth miracle' whilst the Philippines had an episode of 'growth failure' between 1960 and 1988; according to him,

"The main engine of growth is the access to human capital -of knowledge-and the main source of difference in living standards among nations is the difference in human capital. Physical capital accumulation plays an essential but decidedly subsidiary role".

Using a "bottoms-up" approach, we focus not only on the firm's attainment of a least-cost input combination, but also on technology transfer-induced endogenous changes in productivity. The vital elements in the latter are skilled labor intensity (measuring $A C$ ), physical capital intensity (proxying $S S$ ), and the trade intensity (TI, offering the opportunities for capturing a technological bonus). As shown below, for a sector "CP" is an amalgam of $\mathrm{AC}, \mathrm{SS}$ and TI. In the context of European Union's enlargement efforts to give accession to lower-tier countries, this issue is pertinent. SS encapsulates social capital and effects of physical capital amalgamated into one 'catch-all' factor for ease of expositional convenience. According to Dasgupta [25], TFP binds both technology and socio-economic institutions. Sen [26] ascribes important role to lack of social and physical infrastructure. In a simple set up, the model purports to show the mechanism of three pillars for cooperation between high-tier and low-tier economies - a lesson useful from the EU's enlargement perspective (not discussed for parsimony and different focus of current analysis).

A representative firm reaps the benefits of technological improvements embodied in imported inputs. It needs higher level skills to harness the benefits of technological improvements. At the macro level, given the overall human capital stock and structural congruence with the trading partners, the regions participate in trade and reap the technological bonus (TB) out of trade flows (see Cetin and Cincera [27]). Of course, at a given intensity of trade flows, a higher bonus may be achievable if the skill intensity of the work force is higher, which may partially motivate building up additional skills. At the level of a sector, the question is to find out the "optimal" level of skilled labour for a sector so as to make the best use of the "TB" obtainable from trade-mediated technology. Even though the firm chooses an optimal input mix, technical progress in the foreign source is an exogenous phenomenon. This induces a sectoral bias into technical change as skilled labour will have an advantage in extracting the "TB" from spillovers.

Based on the theoretical insights, we adopt a neo-classical growth framework. Let us consider an economy that produces a single homogeneous good " $Y_{t}$ " (output or GDP, synonymously) using composite (i.e., skilled and unskilled composite) labor $(L)$, domestic capital or gross domestic capital formation, GDI, $\left(K^{D}\right)$ and foreign capital of FDI $\left(K^{F}\right)$ so that the aggregate Neoclassical wellbehaved production function is written as: 


$$
Y_{t}=A_{t} F\left(L_{t}, K_{t}^{D}, K_{t}^{F}\right)
$$

where " $A_{t}>0$ " is an index of technological progress (parameter) representing Total Factor Productivity (TFP) index or Hicks-neutral technical progress.

Also, aggregate composite capital stock, $K_{t}=K_{t}^{D}+K_{t}^{F}$.

Subscript " $t$ " refers to unit of time. However, for simplicity we suppress the regional subscript for each country j.

Assuming linear homogeneity (constant returns to scale), this production function can be expressed in per worker (intensive form) terms as:

$$
y_{t}=A_{t} f\left(k_{t}^{D}, k_{t}^{F}\right)
$$

where lower case letters represent per worker values of the corresponding variables. Note that $y_{t}$ is the productivity per worker in period $t$.

Assuming log-linearity and taking a total differential of (1), we derive the following expression for growthaccounting relation as:

$$
\dot{y}_{t} / y_{t}=\dot{A}_{t} / A_{t}+\beta \dot{k}_{t}^{D} / k_{t}^{D}+\gamma \dot{k}_{t}^{F} / k_{t}^{F}
$$

In (3), generically $\dot{x}_{t}=\frac{d x}{d t} \frac{1}{x}$ is the time rate of change of variable $x$ or the growth rate.

The above expression shows that the growth-rate of per capita GDP depends on the growth rates of FDI and GDI intensity per worker and the rate of TFP growth. It is to be noted that the TFP changes, being influenced by shares of FDI and GDI in aggregate output, occur endogenously to escalate the growth in per capita GDP. Under perfect competition in product and factor markets, the coefficients are the corresponding output elasticities (equivalently, factor cost shares of foreign and domestic capital in per capita terms) of FDI and GDI per capita (in terms of growth rates).

The implication of this model is that since at higher level of capital stock, it will be subject to diminishing returns, the countries with lower level of productivity will experience a higher growth as a result of increased FDI. On the other hand, for the advanced countries the growth of productivity will be slower. Thus, this model suggests that the productivity differential across countries will be smaller owing to FDI-induced foreign capital inflows. The convergence of growth rates is in line with the catch-up hypothesis put forward for the newly emerging and rapidly industrializing economies of East and South-East Asia. This has important bearing for the EU's integration effort with potential and candidate member states with lack of appropriate constellation of

\footnotetext{
${ }^{2}$ This version of the paper is based on Das [30] with substantial alteration and improvement on the in-house version being incorporated based on feedbacks from Professor Man-Soo Joo.

${ }^{3}$ Derived from Das [30].
}

enabling factors (Shankar and Shah [28]). With sufficient human capital and skill formation, a country will have ample opportunity to break this diminishing returns and hence, will be able to reap spillover benefits via harnessing the technologically sophisticated capital goods or imported input embodying superior state-of-the-art. Thus, "k" in the above stylizations could be interpreted broadly to encompass human capital or knowledge-capital of superior quality. As Pack and Westphal [29] argued,

"effort is required in using technological information and accumulating technological knowledge...to create new technology. This takes the form of investments in.....effective use of knowledge."

In what follows, we just present an illustrative analytical model to show the role of human capital intensity to absorb sophisticated technology, assuming that physical capital intensity does not hinder the growth process. ${ }^{2}$

\section{A Model of Productivity Bonus ${ }^{3}$}

Newer technology embodied in traded goods demands its own types of skills. The profile of skills embodied in the workers interacts with other inputs and the available state of the art to determine the TFP. The underlying assumption is that workers differ in the appropriateness of their skills to achieve any given productivity level with a particular vintage of technology. Competition ensures that each labour type is paid according to its marginal product.

The incentive of reaping a technological bonus from embodied spillovers modifies the representative firm's choice of an optimal occupational mix. Thus, the bonus hypothesis is: the representative firm, in the process of maximizing profit (or minimizing costs), takes into account the benefits of technological improvements embodied in imported intermediate inputs. Capturing these benefits requires an appropriate mix of skilled and unskilled labour, which is recognized by the representative firm in its production decisions. The benefits available, moreover, depend positively on the structural similarity of the source and the recipient (as measured by the ratio of capital to quality adjusted labour). Technological improvement is exogenous in this theory which is restricted to the propagation of technology. We assume that for a sector "Bonus Embodied Spillover of Technology (BEST)" is achieved in consonance with the representative firm's static optimization exercise: firstly, three variables viz., sectoral skill intensity, structural congruence and trade intensity in production of the sector combine to produce a capture-parameter. This subsequently transforms the potential productivity improvement into an actual productivity bonus-BEST-accrued via the traded intermediates. Figure 1 shows the transmission mechanism behind the productivity bonus.

The production function is generically written as: 


$$
Y=\operatorname{function}\left(M_{F}, M_{D}, L_{S}, L_{U}\right)
$$

where $Y$ : output,

$M_{F}$ : imported material input,

$M_{D}$ : domestic material input,
$L_{S}$ : skilled labour input and

$L_{U}$ : unskilled labour input.

$M$ : composite (aggregate) materials of $M_{F}$ and $M_{D}$. $V$ : Value-added composite of primary factors.

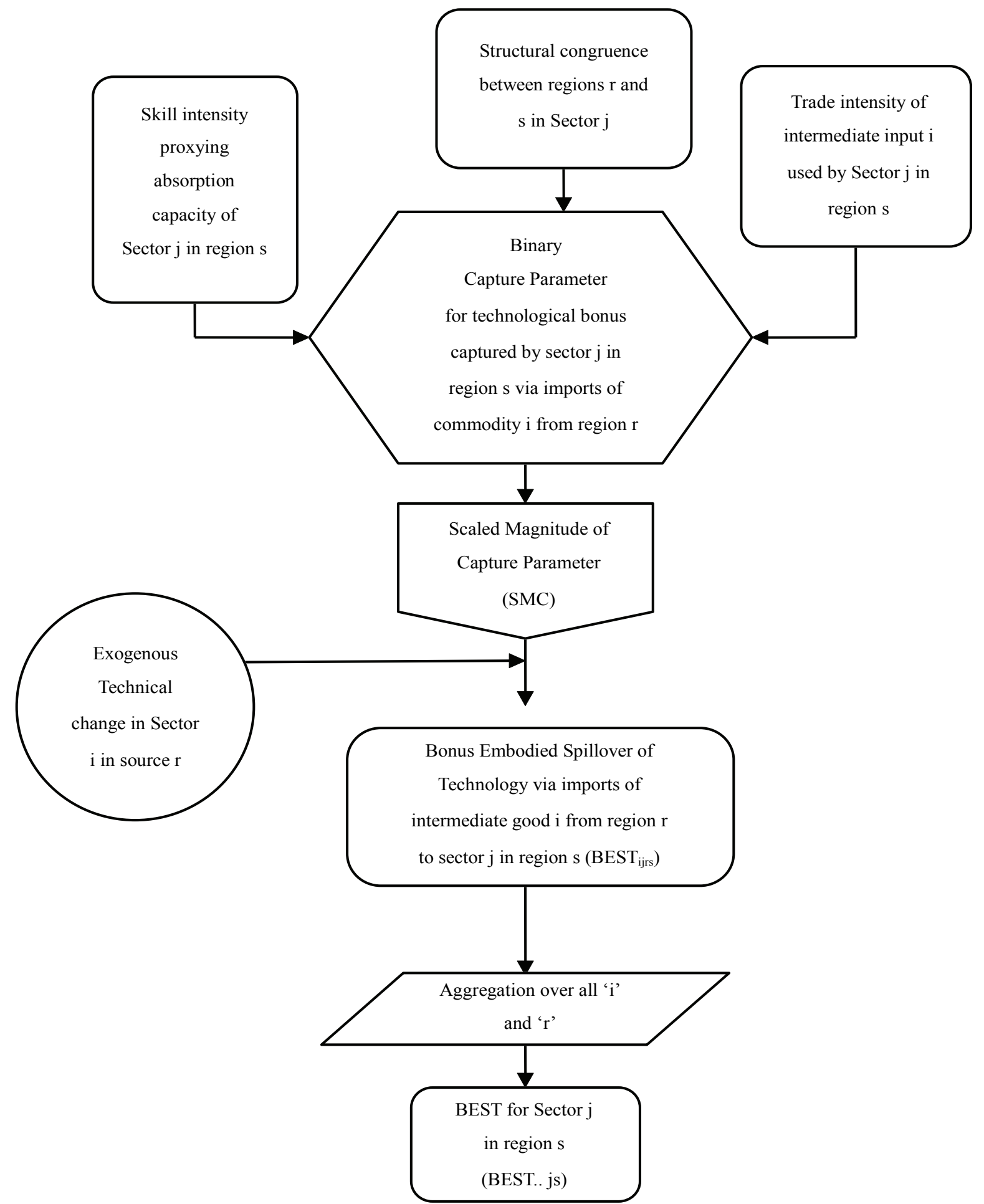

Figure 1. Principal pathways underlying the mechanism of technological bonus capture by sector $\mathrm{j}$ in region $\mathrm{s}$. 
Assuming the production function Leontief (at the top level) in $\mathrm{M}$ and in value added measured in efficiency units, bV:

$$
\mathrm{Y}=\operatorname{Min}\{\mathrm{M}, \mathrm{bV}\}
$$

where:

$$
\begin{aligned}
& M=M_{F}^{\alpha} M_{D}^{(1-\alpha)} \\
& V=L_{S}^{\beta} L_{U}^{(1-\beta)} \\
& b=f \times g \\
& \ln \mathrm{f}=\mathrm{h}\left(\ln \left[\frac{M_{F}}{M_{D}}\right]\right) \\
& \ln \mathrm{g}=\mathrm{H}\left(\ln \left[\frac{L_{S}}{L_{U}}\right]\right) \\
& \mathrm{h}, \mathrm{H}>0 \\
& \mathrm{~h}^{\prime}, \mathrm{H}^{\prime}>0
\end{aligned}
$$

The function $b$ in (8) allows for changes in TFP via two intensity ratios, the import intensity of material inputs and the skill intensity of labor, entering multiplicatively. The optimization problem facing the representative perfectly competitive firm is formalized as:

Maximize Y with respect to $M_{F}, M_{D}, L_{S}, L_{U}$, subject to:

$$
C=P_{F} M_{F}+P_{D} M_{D}+W_{S} L_{S}+W_{U} L_{U}
$$

where $C$ is the cost of inputs, while $P_{F}, P_{D}, W_{S}$, and $W_{U}$ are the prices of the inputs. Note that $P_{F}, P_{D}, W_{S}$, and $W_{U}$ are all exogenous. $C$ is a real anchor in this constant-returns-to-scale world and hence, is set exogenous.

Taking a monotonic logarithmic transformation, maximize $Y$ subject to:

$$
\ln C=\ln \left\{P_{F} M_{F}+P_{D} M_{D}+W_{S} L S+W_{U} L_{U}\right\}
$$

Since (5) is non-analytic, we invoke the (Leontief) restriction (18) below; as a second constraint in the Lagrangean.

$$
\begin{aligned}
& \ln Y=\ln M=\ln b+\ln V \Rightarrow \\
& \alpha \ln M_{F}+(1-\alpha) \ln M_{D} \\
= & \ln b+\beta \ln L_{S}+(1-\beta) \ln L_{U} \Rightarrow \\
& \alpha \ln M_{F}+(1-\alpha) M_{D} \\
= & h\left(\ln M_{F}-\ln M_{D}\right)+H\left(\ln L_{S}-\ln L_{U}\right) \\
& +\beta \ln L_{S}+(1-\beta) \ln L_{U}
\end{aligned}
$$

Form the Lagrangean:

$$
\begin{aligned}
L=\alpha & \ln M_{F}+(1-\alpha) \ln M_{D} \\
& +\Lambda\left\{\alpha \ln M_{F}+(1-\alpha) \ln M_{D}\right. \\
& -\left[h\left(\ln M_{F}-\ln M_{D}\right)+H\left(\ln L_{S}-\ln L_{U}\right)\right. \\
& \left.\left.+\beta \ln L_{S}+(1-\beta) \ln L_{U}\right]\right\}
\end{aligned}
$$

$$
+\lambda\left\{\ln C-\ln \left[P_{F} M_{F}+P_{D} M_{D}+W_{S} L_{S}+W_{U} L_{U}\right]\right\}
$$

The first-order conditions [other than the constraints (15) and (18)] are:

$$
\begin{aligned}
& \frac{\partial L}{\partial \ln M_{F}}=\alpha+\alpha \Lambda-\Lambda h^{\prime}-\lambda P_{F} M_{F} / C=0 \\
& \frac{\partial L}{\partial \ln M_{D}}=(1-\alpha)+\Lambda(1-\alpha)+\Lambda h^{\prime}-\lambda P_{D} M_{D} / C=0 \\
& \frac{\partial L}{\partial \ln L_{S}}=-\Lambda H^{\prime}-\Lambda \beta-\lambda W_{S} L_{S} / C=0 \\
& \frac{\partial L}{\partial \ln L_{U}}=\Lambda H^{\prime}-\Lambda(1-\beta)-\lambda W_{U} L_{U} / C=0
\end{aligned}
$$

Adding (22) and (23) yields:

$$
\Lambda=-\lambda W L / C \quad\left(\text { where } W L=W_{S} L s+W_{U} L_{U}\right)
$$

Adding (20) and (21) yields:

$$
\Lambda=\lambda P_{M M} / C-1 \quad\left(\text { where } P_{M} M=P_{F} M_{F}+P_{D} M_{D}\right)
$$

Solving (20) through (23) for the input shares, we obtain:

$$
\begin{gathered}
P_{F} M_{F} / C=\left\{\alpha(1+\Lambda)-\Lambda h^{\prime}\right\} / \lambda \\
P_{D} M_{D} / C=\left\{(1-\alpha)(1+\Lambda)+\Lambda h^{\prime}\right\} / \lambda \\
W_{S} L_{S} / C=-\Lambda\left(H^{\prime}+\beta\right) / \lambda \\
W_{U} L_{U} / C=\Lambda\left\{H^{\prime}-(1-\beta)\right\} / \lambda \Rightarrow H^{\prime}<(1-\beta)
\end{gathered}
$$

The left-hand sides of (26) through (29) add to unity, while the right-hand sides add to $1 / \lambda$; hence

$$
\lambda=1 \text {. }
$$

Using (30) in (24),

$$
\Lambda=-W L / C=-S_{L}=\text { the share of labour in cost }
$$

Denoting the cost shares of the four inputs by $S_{F}, S_{D}$, $S_{S}, S_{U}$, from (30) and (26) through (29) we see:

$$
\begin{aligned}
& S_{F}=\alpha S_{M}+h^{\prime} S_{L} \\
& S_{D}=(1-\alpha) S_{M}-h^{\prime} S_{L} \\
& S_{S}=\left(H^{\prime}+\beta\right) S_{L} \\
& S_{U}=\left(1-H^{\prime}-\beta\right) S_{L}
\end{aligned}
$$

The quantity component of the shares is determined [via (5)] by output. That is:

$$
\begin{aligned}
S_{L} & =\mathrm{W} \times(\mathrm{bV}) / \mathrm{C} \\
& =\mathrm{WY} / \mathrm{C}
\end{aligned}
$$

The value-added price index $\mathrm{W}$ is 


$$
W=\frac{W_{S} L_{S}+W_{U} L_{U}}{b L_{S}^{\beta} L_{U}^{(1-\beta)}}
$$

Similarly for materials:

$$
\begin{aligned}
S_{M} & =P_{M} \times \mathrm{M} / \mathrm{C} \\
& =P_{M} \mathrm{Y} / \mathrm{C}
\end{aligned}
$$

where composite material prices is given by:

$$
P_{M}=\frac{P_{F} M_{F}+P_{D} M_{D}}{M_{F}^{\alpha} M_{D}^{(1-\alpha)}}
$$

\section{Numerical Illustration ${ }^{4}$}

\subsection{The Data and Parameter Setting}

Our analytical model developed above indicates that several inferences could be drawn from patterns of changes in the system. Thus, we perform some numerical simulation to show the impact of a technology shock (TFP) on the productivity improvement. The problem is approached in a partial equilibrium set up to see what type of changes prevails in the model. We illustrate the mechanism on the basis of a hypothetical data set with admissible values-presented in Tables $\mathbf{1}$ and 2 . We have assigned admissible values to the parameters of the model, $\alpha$ and $\beta$. Tables 1 and 2 present the specific initial settings or base-case scenario.

The base-case scenario in Tables $\mathbf{1}$ and $\mathbf{2}$ is a solution of the share Equations (32)-(35) above. The impact of TFP improvement on endogenous productivity enhancement is traced via changes in " $b$ " in the wake of several perturbations as specified in the experiments.

\subsection{TFP Simulation}

We simulate the effect of 5 and 10 percent TFP shock. Following the perturbation, the changed initial configurations of the variables are given in Table 3 .

The 10 percent Hicks-Neutral shock is represented by the 10 percent increase in ' $b$ ' $(2.724 / 2.4764=1.10)$ between Tables 1 and 3. As this shock is factor-neutral by nature, it affects the 'size' of the composite value-added whilst the composition of value-added (measured in conventional units) remain unaltered. Thus, because of Hicks-Neutrality skill-unskilled labour ratio between Tables 1 and $3(4 / 8=0.5=3.739 / 7.478)$ remains unchanged. With fixed cost and prices kept fixed at the original level, the TFP improvement translates into a fall in the valueadded measured in conventional units-compare the values for "V" in Tables 1 and 3 -implying each productive factor inputs are required in less amount in physical terms. With cost being held fixed and given no change in the relative prices in the post-shock scenario, as $\mathrm{V}$ falls $\mathrm{M}$ has to increase to satisfy the constraint for fixed cost. Comparing the last column in these two tables, we infer that in quality-adjusted term, however, real value added increases. This is because the level of productivity bonus [i.e., value of "b"] is augmented from 2.48 to 2.72 . This, in turn, increases the effective value- added [i.e., "bV"]. Following the Leontief fixed-coefficient technology at the top-most level, the usage of composite material inputs goes up by the same magnitude as ' $b V$ ' - see third column in Tables 2 and 3. Also, gross output [Y] increases by about 2.8 percent - see fourth column in Tables 1 and $3(15.439 / 15.014=1.028)$. Results for $5 \%$ shock could be explained analogously; however, as

Table 1. Initial scenario for the representative firm.

\begin{tabular}{ccccccccc}
\hline $\mathrm{M}_{\mathrm{F}}$ & $\mathrm{M}_{\mathrm{D}}$ & $\mathrm{M}$ & $\mathrm{Y}_{\mathrm{j}}$ & $\mathrm{V}$ & $\mathrm{L}_{\mathrm{S}}$ & $\mathrm{L}_{\mathrm{U}}$ & $\mathrm{b}$ & $\mathrm{b}_{\mathrm{V}}$ \\
\hline 8 & 19.664 & 15.014 & 15.014 & 6.063 & 4 & 8 & 2.476 & 15.014 \\
\hline
\end{tabular}

Table 2. Prices and Parameter setting for the representative firm.

\begin{tabular}{ccccccc}
\hline $\mathrm{W}_{\mathrm{S}}$ & $\mathrm{W}_{\mathrm{U}}$ & $\mathrm{P}_{\mathrm{F}}$ & $\mathrm{P}_{\mathrm{D}}$ & $\mathrm{C}[$ exogenous] & $\alpha$ & $\beta$ \\
\hline 1 & 1 & 1 & 1 & 39.665 & 0.3 & 0.4 \\
\hline
\end{tabular}

Table 3. Post-shock scenario for the representative firm and the impacts of TFP shocks.

\begin{tabular}{ccccccccccc}
\hline Variables & $\mathrm{M}_{\mathrm{F}}$ & $\mathrm{M}_{\mathrm{D}}$ & $\mathrm{M}$ & $\mathrm{Y}_{\mathrm{j}}$ & $\mathrm{V}$ & $\mathrm{L}_{\mathrm{S}}$ & $\mathrm{L}_{\mathrm{U}}$ & $\mathrm{b}$ & $\mathrm{f}$ & $\mathrm{g}$ \\
\hline 10\% shock & 8.226 & 20.221 & 15.439 & 15.439 & 5.667 & 3.739 & 7.478 & 2.724 & 1.50 & 1.65 \\
$5 \%$ shock & 8.116 & 19.952 & 15.234 & 15.439 & 5.858 & 3.865 & 7.730 & 2.600 & 1.50 & 1.65 \\
\hline
\end{tabular}

\footnotetext{
${ }^{4}$ The discussion and arguments draws partly on the in-house version of the article in Research Institute of Digital Economics, Hanyang University, Ansan. We need to report this to highlight the differences with other counterfactual simulations that we present below in details. However, this reproduction is for facilitating understanding of the theoretical insight via numerical example.
} 
conjectured the lower TFP shock reduces the capture and the output compared to $10 \%$-scenario. The sensitivity analysis with respect to TFP shock does not alter the direction of causality in the results. Keeping the skilledunskilled factor intensities and the foreign-domestic intermediate input intensities unaltered, we see that the larger is the size of the TFP shock (i.e., 10\% as compared to $5 \%$ ), the larger is the accrual of productivity bonus ( $\boldsymbol{B} \boldsymbol{E S T})$. In other words, "b" augments from 2.60 to 2.72 in case of doubling the size of transmitted productivity shock. This motivates us to perform further scenario analysis to examine how variations in the intensities of factor usage in the presence of this TFP-augmentation (5\%) could inflate the productivity bonus.

\subsection{Design of Counterfactuals and Numerical Analysis}

We keep the productivity shock at 5\% (we call it TFPbase case) and consider the following scenarios: ${ }^{5}$

1) " $L_{s}$ " remains the same: in this case, we keep it unaltered as in Table 1, Column 6 (that is, it is not reduced as in Table 3, Column 7, TFP-base case). Thus, the constrained cost-minimization by the firm entails reduction in $\mathrm{Su}$, increase in $\mathrm{S}_{\mathrm{s}}$ (and hence, in $\mathrm{g}$ via Equation (10)). As "f" (via (9)) remains the same, bonus "b" increases to 2.60 (from 2.53) and Y goes up to 15.20 from initial base case value of 15.01 (see Table 4, row 2).

Inference I: increase in skill-intensity improves AC and leads to improvement of the productivity bonus despite TFP shock being fixed at 5\% level. Skill-intensity is crucial for assimilating productivity benefits.

2) " $L_{u}$ " is increased: to 10 so that skill intensity of the firm falls. Constrained cost-minimization in the presence of 5\% TFP entails reduction of $\mathrm{L}_{\mathrm{s}}$ and fall in material input usage $\left(\mathrm{M}_{\mathrm{F}}\right.$ and $\mathrm{M}_{\mathrm{D}}$ shrink) compared to both original base-case and TFP-base case (see row 3, Table 4). As expected, "g" and f fall (via Equations (9) and (10)), causing the bonus " $b$ " to dissipate. This leads to fall in "bV" and "Y".

Inference II: decrease in skill-intensity reduces AC and leads to dissipation of the productivity bonus despite the presence of TFP shock being fixed at 5\% level. Also, decline in foreign intermediate input intensity leads to shrink in the productivity capture.

3) Foreign intermediate input $\left(M_{F}\right)$ is increased: here traded intermediates is augmented whereas domestically sourced input $\left(\mathrm{M}_{\mathrm{D}}\right)$ input is decreased causing, via the representative firm's constrained-cost minimization choices of factor inputs, share of materials to increase and share of value-added composite to fall (see row 4, Table 4). This led to increase in " $f$ " substantially whereas "g" remained the same as in both the base-cases. It led to increase in the bonus capture (via (8)) and resultant increase in final output "Y" (row 4, Table 4).

Inference III: increase in imported intermediate inputs embodying sophisticated technology increases trademediated technology spillover and leads to rise in the productivity bonus even with fixed 5\% TFP shock and same skill-intensity levels. Trade intensity is conducive for reaping productivity bonus.

4) " $L_{s}$ " is increased, while keeping $L_{u}$ unaltered: in this scenario, the representative firm's optimization solution leads to increase in skill intensity (hence, in AC) whereas trade-intensity (f) remains almost the same. This led to increase in $\mathrm{S}_{\mathrm{s}}$, bonus (b) and hence, in output " $\mathrm{Y}$ " (see row 5, Table 4).

Inference IV: increase in skill-intensity enables to reap the productivity bonus via assimilation of imported intermediate inputs embodying sophisticated technology. This leads to rise in the level of final output even with fixed 5\% TFP shock and trade intensity.

5) " $M_{F}$ " is increased and " $M_{D}$ " is fixed at the original base-value: in this case, we see that "f" increases (as trade intensity goes up), but skill-intensity remains the same (g is unaltered). This leads to rise in the productivity spillover "b" causing output "Y" to grow (see row 6, Table 4).

Table 4. Post-shock scenarios for the representative firm under different scenarios with $5 \%$ TFP shock (TFP-base case).

\begin{tabular}{cccccccccccc}
\hline Variables & $\mathrm{M}_{\mathrm{F}}$ & $\mathrm{M}_{\mathrm{D}}$ & $\mathrm{M}$ & $\mathrm{Y}_{\mathrm{j}}$ & $\mathrm{V}$ & $\mathrm{L}_{\mathrm{S}}$ & $\mathrm{L}_{\mathrm{U}}$ & $\mathrm{b}$ & $\mathrm{f}$ & & $\mathrm{g}$ \\
\hline Scenario 1) & 8.09 & 19.91 & 15.20 & 15.20 & 5.91 & 4 & 1.66 & 2.60 & 1.50 & 1.69 \\
Scenario 2) & 7.56 & 18.42 & 14.10 & 14.10 & 6.71 & 3.68 & 10 & 2.32 & 1.43 & 1.40 \\
Scenario 3) & 13.91 & 17.39 & 16.30 & 16.30 & 4.22 & 2.80 & 5.60 & 3.85 & 2.23 & 1.65 \\
Scenario 4) & 9.16 & 22.50 & 17.18 & 17.18 & 4.02 & 4.01 & 4 & 4.09 & 1.50 & 2.72 \\
Scenario 5) & 8.69 & 19.66 & 15.39 & 15.39 & 5.72 & 3.77 & 7.54 & 2.70 & 1.56 & 1.65 \\
Scenario 6) & 8.07 & 19.83 & 15.14 & 15.14 & 5.92 & 3.76 & 8 & 2.56 & 1.50 & 1.61 \\
Original base-case & 8 & 19.66 & 15.01 & 15.01 & 6.06 & 4 & 8 & 2.47 & 1.50 & 1.65 \\
TFP-base case & 8.12 & 19.95 & 15.23 & 15.23 & 5.86 & 3.86 & 7.73 & 2.60 & 1.50 & 1.65 \\
\hline
\end{tabular}

\footnotetext{
${ }^{5}$ Original base case scenario is the one without any TFP shock. TFP-base case is the one with only 5\% TFP shock. Since 5\% and $10 \%$ TFP shock generates the same direction of causality of results, only size or the magnitude of impacts differ, in the context of these series of counterfactuals this does not undermine our purpose. It is obvious that the higher doses of TFP coupled with those simulations would change the magnitude of accrual of bonus.
} 
Inference $\mathrm{V}$ : increase in trade-intensity enables to reap the productivity bonus embedded in the imported intermediate inputs containing sophisticated technology. This leads to rise in the level of final output even with fixed 5\% TFP shock and similar skill-unskilled labor shares.

6) " $L_{s}$ " decreases, but " $L_{u}$ " remains at the original base-case value: in this counterfactual case, $\mathrm{L}_{\mathrm{s}}$ decreases so that $\mathrm{S}_{\mathrm{s}}$ falls and hence, skill intensity declines. As $\mathrm{M}_{\mathrm{d}}$ and $\mathrm{M}_{\mathrm{f}}$ do not alter much, following the firm's constrained cost-minimization exercise, " $\mathrm{f}$ " remains unaltered while " $\mathrm{g}$ " is reduced. Thus, the bonus magnitude " $\mathrm{b}$ " shrinks compared to TFP-base case. But as there is initial 5\% TFP improvement, this causes output "Y" to register marginally higher level than the original base-case value (compare row 7, Table 4 with row 8). This is lower than TFP-base case as there is a fall in "g" following decline of skill-unskilled ratio.

Inference VI: decrease in skill-intensity in the presence of unchanged trade-intensity causes less chance to reap the productivity bonus embedded in the imported intermediate inputs. In this case, rise in the level of final output is induced by 5\% TFP shock despite declining skill composition and similar level of trade intensity.

All these inferences are instrumental in understanding the working of the theoretical model developed in this paper. The numerical illustration of the model confirms our conjecture that trade, indigenous skill-induced adoptive capabilities as well as technological sophistication are important forces for sustained growth and development. All these three channels facilitate learning of technologies of recent vintage. They mutually reinforce each other to translate into higher growth of output.

\section{Conclusions}

This paper presents and numerically implements a theoretical model of endogenous capture of technical change originating in the source of knowledge-creation (assumed exogenous). Numerical simulation confirms that: increases in the intensity of skilled labor in the input mix improves the absorptive capacity of the work force; the amount of technology captured increases with the import intensity of the material inputs while technological change is vehicled via foreign intermediates; increase in both types of intensities complements each other to augment the bonus capture; only technological change cannot deliver the potential benefits unless the input mixes are optimally chosen by the firm while making cost-minimization decision. We have explored their effects in harnessing the trade-induced technology flows. We show that capture-parameter is the propellant force for assimilation of transmitted technology. Further work along these lines will involve mounting the full scale simulations in a higher dimensional model and integrating a dynamic aspect of R\&D-creation and its propaga- tion. This work has important implications for technology policy and planning as well as for trade or regional integration, for example, in the context of European Union's accession program under Europe 2020 aimed at social cohesion, competitiveness, skill formation, and R\&D (Shankar and Shah [28]). Often, the necessity of political and social integration as precursor of successful monetary union is stressed. A systemic view is warranted for pursuing this objective. The model elicits heuristically that technology policy, trade policy and macroeconomic management needs a synergistic planning to achieve sustained growth. Trade, per se, is insufficient for achieving the growth dividends. Trade creates the opportunities for sustained development via industrialization and technology transfer; however, developing adequate socio-institutional framework, educational attainment and skill formations, inter alia, are necessary for seizing plethora of opportunities.

\section{References}

[1] W. Keller, "International Technology Diffusion." Journal of Economic Literature (AEA), Vol. 42, No. 3, 2004, pp. 752-782.

[2] J. Eaton and S. Kortum, "Trade in Ideas: Patenting and Productivity in the OECD," Journal of International Economics, Vol. 40, No. 3-4, 1996, pp. 251-278.

[3] J. Eaton and S. Kortum, "Engines of Growth: Domestic and Foreign Sources of Innovation," Japan and the World Economy, Vol. 9, No. 2, 1997, pp. 235-259.

[4] D. T. Coe, E. Helpman and A. W. Hoffmaister, "NorthSouth R\&D Spillovers," Economic Journal, Vol. 107, No. 440, 1997, pp. 134-149.

[5] D. T. Coe, E. Helpman and A. W. Hoffmaister, "International R\&D Spillovers and Institutions," IMF Working Paper WP/08/104, IMF, 2008, pp. 1-35.

[6] World Bank, "World Development Report 1998/9: Knowledge for Development," New York, Oxford University Press, 1999.

[7] World Bank, "Global Economic Prospect 2008: Technology Diffusion in the Developing World," Washington D.C., 2008.

[8] M. P. Connolly, "The Dual Nature of Trade: Measuring its Impact on Imitation and Growth," Duke University Department of Economics Working Paper, Durham, North Carolina, No. 97-34, 1998, pp. 1-28.

[9] P. Guerrieri and C. Milana, "Changes and Trends in the world Trade in High-Technology Products," Cambridge Journal of Economics, Vol. 19, No. 1, 1995, pp. 225-242.

[10] B. Hoekman and B. Javorcik, "Global Integration and Technology Transfer," Palgrave MacMillan, New York, 2006.

[11] G. G. Das, “Absorptive Capacity and Structural Congruence: The Binding Constraints on Technology Transfer-An Analytical Survey of the Underlying Issues," Korean Journal of Policy Studies, Vol. 15, No. 2, 2001, 
pp. 117-140.

[12] G. G. Das, "Trade, Technology and Human Capital: Stylised Facts and Quantitative Evidence," World Economy, Vol. 25, No. 2, February 2002, pp. 257-281.

[13] G. G. Das, "Modeling Sectoral and Welfare Impacts of Information Technology Spillovers: A Tale of Two Souths," Indian Journal of Economics and Business, Serial Publications, Vol. 7, No. 2, December 2008, pp. 195205.

[14] W. M. Cohen and D. A. Levinthal, "Absorptive Capacity: A New Perspective on Learning and Innovation," Administrative Science Quarterly, Vol. 35, No. 1, March 1990, pp. 128-152.

[15] W. M. Cohen and D. A. Levinthal, "Innovation and Learning: The Two Faces of R\&D," Economic Journal, Vol. 99, No. 397, September 1989, pp. 569-596.

[16] R. R. Nelson and H. Pack, "The Asian Miracle and Modern Growth Theory," Economic Journal, Vol. 109, No. 457, July 1999, pp. 416-436.

[17] R. E. Evenson and. L. E. Westphal, "Technological Change and Technology Strategy," In: J. R. Behrman and T. N. Srinivasan Eds., Handbook of Development Economics, Vol. 3, Chapter 37, Elsevier Science, 1995, pp. 2209-2299.

[18] R. R. Nelson, "On Technological Capabilities and their Acquisition," In: R. E. Evenson and G. Ranis Eds., Science and Technology, Lessons for Development Policy, Westview Special Studies in Science, Technology, and Public Policy, 1990, pp. 71-80.

[19] H. van Meijl and F. van Tongeren, "Trade, Technology Spillovers, and Food Production in China," Weltwirtschaftliches Archiv, Vol. 134, No. 3, 1998, pp. 443449.

[20] G. G. Das, "Embodied Technology Transfer via International Trade and Disaggregation of Labour Payments by Skill Level: A Quantitative Analysis in GTAP Framework," 3rd Annual GTAP Conference in Global Economic Analysis Jointly Organized, the Centre of Policy
Studies, Monash University, Melbourne, Australia and the Centre for Global Trade Analysis, Purdue University, West Lafayette, June 2000, pp. 1-20.

[21] G. M. Grossman and E. Helpman, "Innovation and Growth in the Global Economy," The MIT Press, Cambridge, 1991.

[22] R. E. Lucas Jr, "Making a Miracle," Econometrica, Vol. 61, No. 2, March 1993, pp. 251-72.

[23] R. E. Lucas Jr, "On the Mechanics of Economic Development," Journal of Monetary Economics, Vol. 22, No. 1, 1998, pp. 3-42.

[24] S. Kosempel, "Interaction between Knowledge and Technology: A Contribution to the Theory of Development," Canadian Journal of Economics, Vol. 40, No. 4, 2007, pp. 1237-1260.

[25] P. Dasgupta, "A Matter of Trust: Social Capital and Economic Development," Annual World Bank Conference in Development Economics $(A B C D E)$, Seoul, May 2009, pp. 1-47.

[26] A. K. Sen, "Infrapoverty," Meeting Presentation for Report: Making Infrastructure Work for the Poor, Japan-UNDP, UN, March 2006, pp. 1-6.

[27] D. Cetin and M. Cincera, "Mutual Dependence of R\&D and Trade," Working Paper, Joint Research Centre-IPTS, European Commission, and TED Conference Paper, Izmir, May 2010.

[28] R. Shankar and A. Shah, "Lessons from the European Union Policies for Regional Development," The World Bank Policy Research Working Paper, WPS 4977, Washington DC, 2009, pp. 1-47.

[29] H. Pack and L. E. Westphal, "Industrial Strategy and Technological Change: Theory versus Reality," Journal of Development Economics, Vol. 22, No. 1, 1986, pp. 87128.

[30] G. G. Das, "Trade, Endogenous Technology Capture and Induced Productivity: A Numerical Analysis," Ride Journal of Economics and Business (Korean), Hanyang University, Ansan Campus, Seoul, Vol. 8, 2003, pp. 223-246. 